\title{
Vasitis nodosa and associated clinical findings
}

\author{
LYNN HIRSCHOWITZ, J RODE, J GUILLEBAUD, * W BOUNDS, ${ }^{*}$ EILEEN MOSS \\ From the Bland-Sutton Institute of Pathology, University College and Middlesex School of Medicine, and ${ }^{*}$ the \\ Margaret Pyke Centre, London
}

SUMMARY To establish the prevalence of vasitis nodosa in patients who had undergone vasectomy segments of vas deferens resected from 40 patients at the time of vasectomy reversal were examined histologically and immunohistochemically. The findings were correlated with clinical history and postoperative outcome. Controls comprised segments of normal vas deferens excised at vasectomy. Twenty of the 40 vasovasostomy specimens showed vasitis nodosa; in 13 this was associated with sperm granulomas and in two with spermatocoeles. The vasitis nodosa was characterised by multiple small ductules extending from the central lumen of the vas into the muscle layers and adventitia. In 14 cases there was mucinous metaplasia of the epithelium lining the ductules. The number of nerve fibres in the submucosa and muscle layers was reduced after vasectomy. In patients with vasitis, however, hyperplasia of nerve fibres in the adventitia (16 of 20 cases) and formation of neuromas were seen. Nerve fibre hyperplasia was seen in only one, and sperm granulomas and spermatocoeles in none of the 20 specimens without vasitis nodosa.

The development of vasitis nodosa was independent of the patients' age or the interval between vasectomy and reversal. The restoration of fertility did not seem to be affected by previous vasitis nodosa.

In 1943 Benjamin et al proposed the term "vasitis nodosa" to describe a benign disorder, characterised macroscopically by nodularity of the vas deferens, and microscopically by perivasal proliferation of tubules lined with epithelium and stromal inflammation. ${ }^{1}$ The pathological similarity of this disorder to salpingitis isthmica nodosa was noted. In some cases the pronounced epithelial atypia, mitotic activity, and neural or vascular invasion by the tubules may simulate carcinoma. ${ }^{2-5}$ Associated abnormalities may include suture and sperm granulomas. ${ }^{6}$ Vasitis nodosa has been implicated as a cause of late failure of vasectomy ${ }^{27}$; in these cases the proliferating ductules are thought to re-establish the patency of the vas.

Vasitis nodosa is seen most commonly in the segments of vas deferens resected at the time of vasectomy reversal but has also been described in association with primary infertility, ${ }^{8}$ after herniorrhaphy or prostatectomy, and in a patient with severe chronic cystitis and a large bladder diverticulum. ${ }^{2}$

In this study we examined segments of vas deferens from patients undergoing vasectomy reversal. Our aims were (i) to establish the prevalence of vasitis nodosa; (ii) to determine whether the patients' ages or the interval between vasectomy and reversal were

Accepted for publication 1 December 1987 related to the development of this disorder; (iii) to document any associated histological changes; and (iv) to assess the effect, if any, on the subsequent restoration of fertility.

\section{Material and methods}

Resected segments of vas deferens were received from 40 patients who had undergone elective vasectomy reversals at the Middlesex Hospital between July 1983 and April 1984. The patients ranged in age from 28 to 55 years. The vasectomies had been performed eight months to 14 years earlier. At the time of clinical examination before the reversal procedure, the examining physician recorded the presence of any palpable lumps and associated local pain or tenderness at the reversal site. Reversals were unilateral in 35 of the 40 patients and bilateral in the remaining five. Testicular biopsy specimens were taken from 30 of the 40 patients.

Segments of histologically normal vas deferens resected during routine vasectomies were used as controls. All tissues were fixed in $10 \%$ phosphate buffered formalin and processed to paraffin wax. Sections cut $4 \mu \mathrm{m}$ in thickness were stained with haematoxylin and eosin and with alcian blue-periodic acid Schiff/diastase. The peroxidase antiperoxidase 
method was used to immunostain sections with polyclonal rabbit anti-PGP $9 \cdot 5$. This antiserum specifically labels neurons, neuroendocrine cells, and nerve fibres. ${ }^{9}$

The patients' sperm counts were monitored at three to four monthly intervals for six to 15 months after vasovasostomy and any pregnancies in their spouses were recorded.

An unpaired Student's $t$ test was used to compare the age of patients with and without vasitis nodosa, and also the interval between vasectomy and reversal in these two groups. The significance of the associations between vasitis nodosa and other pathological abnormalities was analysed in $2 \times 2$ contingency tables by $\chi^{2}$ test.

\section{Results}

\section{VASITIS NODOSA}

In 20 of the 40 specimens varying numbers of tubules lined by columnar or cuboidal epithelium extended from the vas into the surrounding muscle and perivasal connective tissue (table 1 , fig 1). In most cases the lining epithelium of the tubules was well differentiated but in the more florid cases of vasitis nodosa the nuclei were hyperchromatic, the nuclear: cytoplasmic ratio was increased, and occasional cells were in mitosis. In eight cases tubules extended into perivasal nerve fascicles (figs $2 a$ and $b$ ) but there was no evidence of vascular invasion. In only four of the specimens with vasitis nodosa were there no associated histological lesions. In the remaining cases vasitis nodosa was accompanied by sperm granulomas, abnormalities in the innervation of the vas, or mucinous metaplasia in the proliferating ductules.

\section{SPERM GRANULOMAS}

These were only present in 13 cases with vasitis nodosa (table 1, fig 3). The granulomas consisted of poorly circumscribed aggregates of chronic inflammatory cells and histiocytes surrounding collections of extravasated spermatozoa. In some cases the aggregates of chronic inflammatory cells were admixed with ceroid-containing histiocytes. Ceroid pigment in the granulomas of vasitis nodosa results

Table 1 Histological changes in excised segments of vas: association with vasitis nodosa

\begin{tabular}{llll}
\hline & $\begin{array}{l}\text { With } \\
\text { vasitis } \\
(n=20)\end{array}$ & $\begin{array}{l}\text { Without } \\
\text { vasitis } \\
(n=20)\end{array}$ & p value \\
\hline $\begin{array}{l}\text { Sperm granuloma } \\
\begin{array}{l}\text { Nerve hyperplasia/ } \\
\text { neuromas }\end{array}\end{array}$ & 13 & 0 & $\mathrm{p}<0.0001$ \\
$\begin{array}{l}\text { Mucinous metaplasia } \\
\text { Suture granuloma }\end{array}$ & 16 & 1 & $\mathrm{p}<0.0001$ \\
Spermatocoele & 8 & 0 & $\mathrm{p}=0.17$ \\
\hline
\end{tabular}

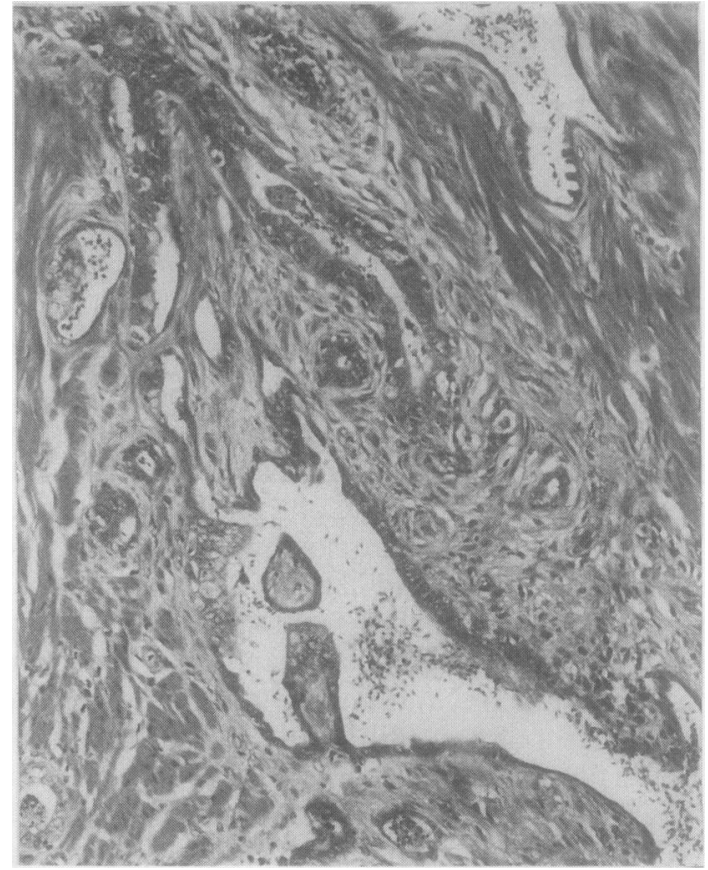

Fig 1 Section through resected segment of vas deferens showing branching ductules characteristic of vasitis nodosa. Ductules extend into muscularis of vas. Note presence of spermatozoa in some ductules. (Haematoxylin and eosin.)

from the degradation of lipids which are present in spermatozoa. ${ }^{2}$

\section{SPERMATOCOELE}

This was observed in only two of the specimens, both with vasitis nodosa, and consisted of numerous spermatozoa in a cystic cavity lined by a single layer of flattened epithelium.

\section{SUTURE GRANULOMA}

Granulomas containing suture material and foreign body giant cells were more common in the group with vasitis than in the group without, the prevalence being eight of 20 and four of 20 , respectively, but this difference was not significant $\left(\chi^{2}=1.9, p=0.17\right)$ (table 1).

\section{ABNORMALITIES IN THE INNER VATION OF THE VAS}

The pattern of innervation was assessed subjectively in sections stained immunohistochemically with antiserum to PGP 9.5 (table 1). All of the specimens obtained at vasectomy reversal showed an obvious reduction in the number of nerve fibres present in the submucosa and the muscle layers. In the cases with 


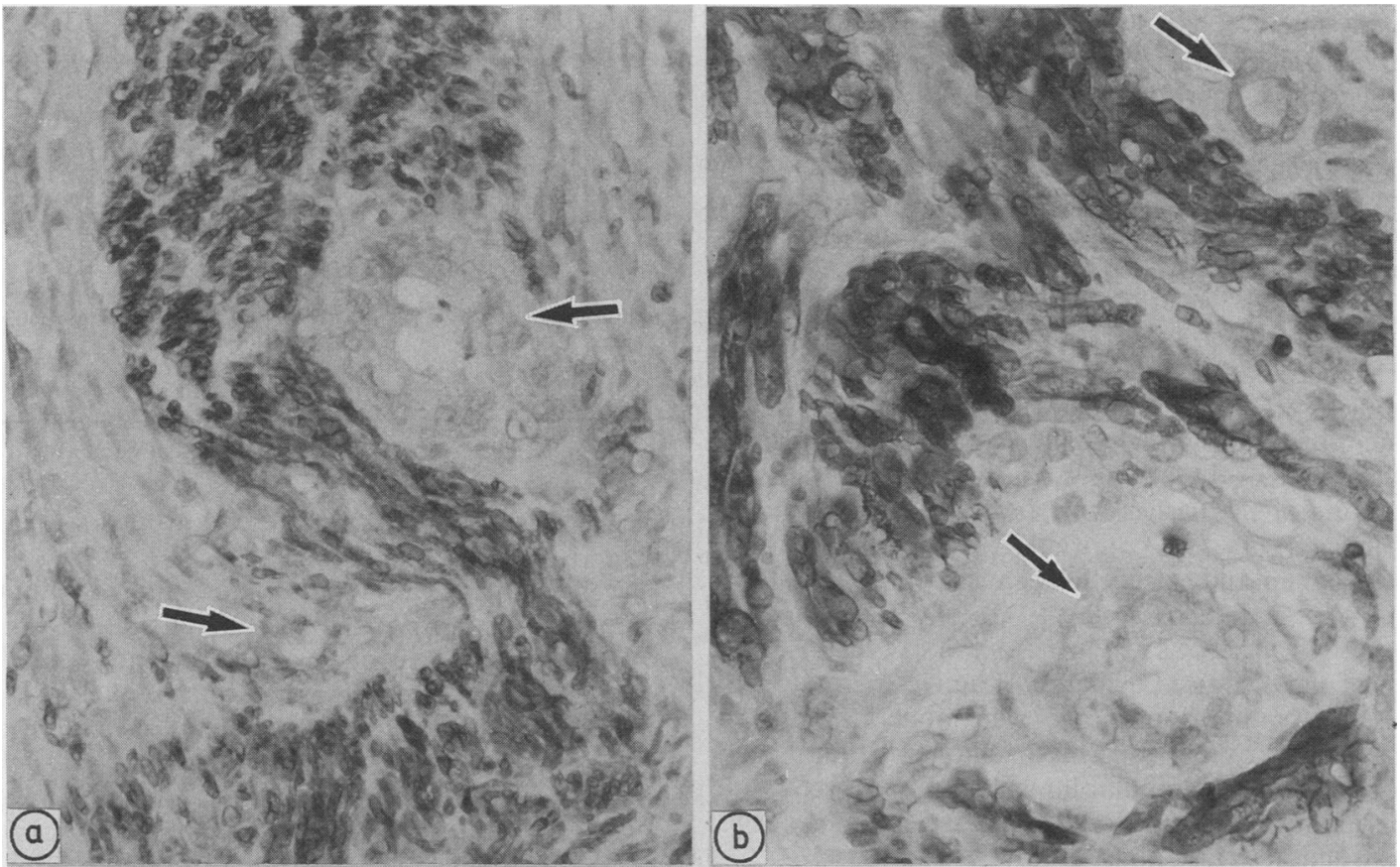

Figs $2 \mathrm{a}$ and $\mathrm{b}$ Perivasal nerve fascicles immunostained for PGP 9.5 showing infiltration by ductules (arrows). (Peroxidase antiperoxidase.)

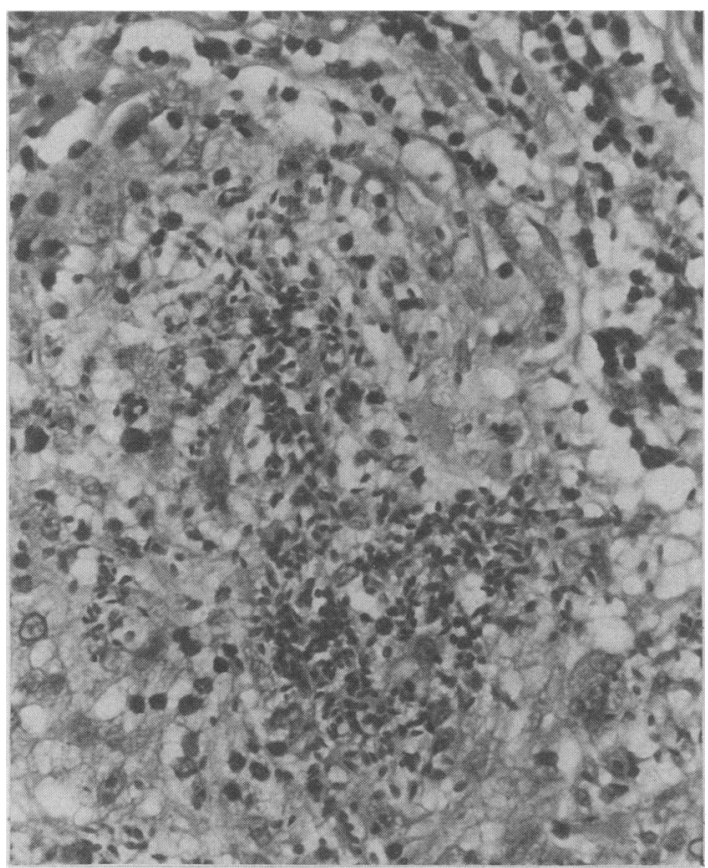

Fig 3 Section of sperm granuloma associated with vasitis nodosa. Central aggregate of spermatozoa is surrounded by macrophages and lymphocytes. (Haematoxylin and eosin.)

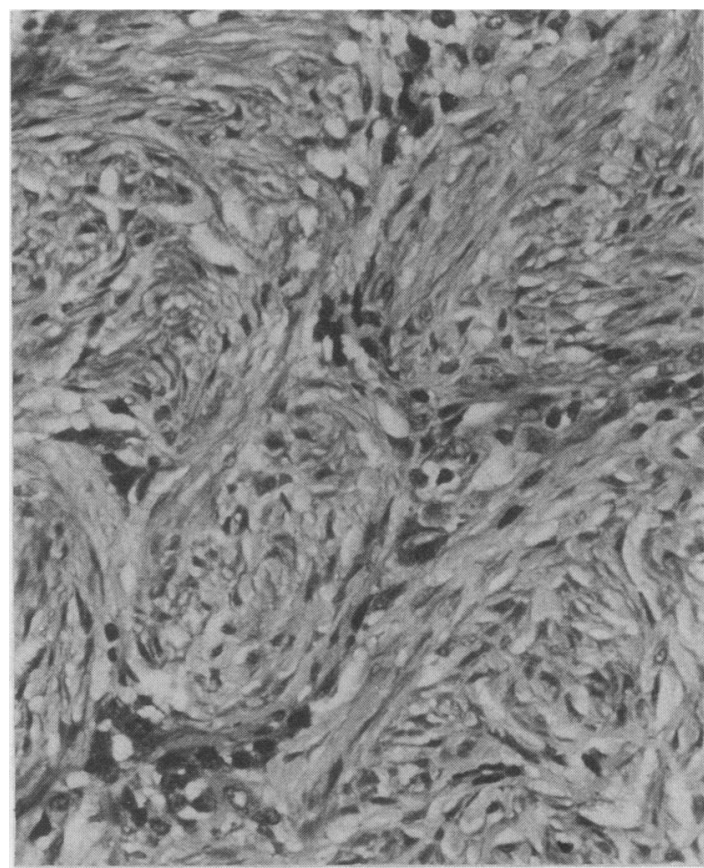

Fig 4 Section through intertwining nerve fibres of neuroma in wall of vas. Some mononuclear inflammatory cells are present. (Haematoxylin and eosin.) 
vasitis nodosa, however, there were many enlarged nerve fascicles in the adventitia of the vas. Some of these formed neuromas (fig 4) consisting of randomly orientated, intertwining bundles of nerve fibres. Hyperplasia of the nerve fibres in the adventitia, with or without neuroma formation, was present in 16 of the specimens with, but in only one of those without vasitis nodosa $\left(\chi^{2}=23.02, p<0.0001\right)$.

\section{MUCINOUS METAPLASIA}

The columnar epithelial lining of the proliferating tubules was, in part, replaced by well differentiated mucin-secreting epithelium (table 1 , fig 5). This feature was noted in 14 of the cases with vasitis nodosa. Staining of the tissues with alcian blue and periodic acid Schiff/diastase confirmed the presence of both intracellular and extracellular mucin.

\section{TESTICULAR BIOPSY SPECIMENS}

All of these showed evidence of active spermatogenesis. The seminiferous tubules were moderately dilated and some of the spermatogenic epithelium had sloughed into the tubular lumena and was mixed with spermatids. This appearance was thought to be due to obstruction to testicular outflow. ${ }^{10}$

The mean age of patients with vasitis nodosa was 38.4 years (SD 3.5) and of those without, 38.8 years (SD 7-3) (table 2). The interval between vasectomy and

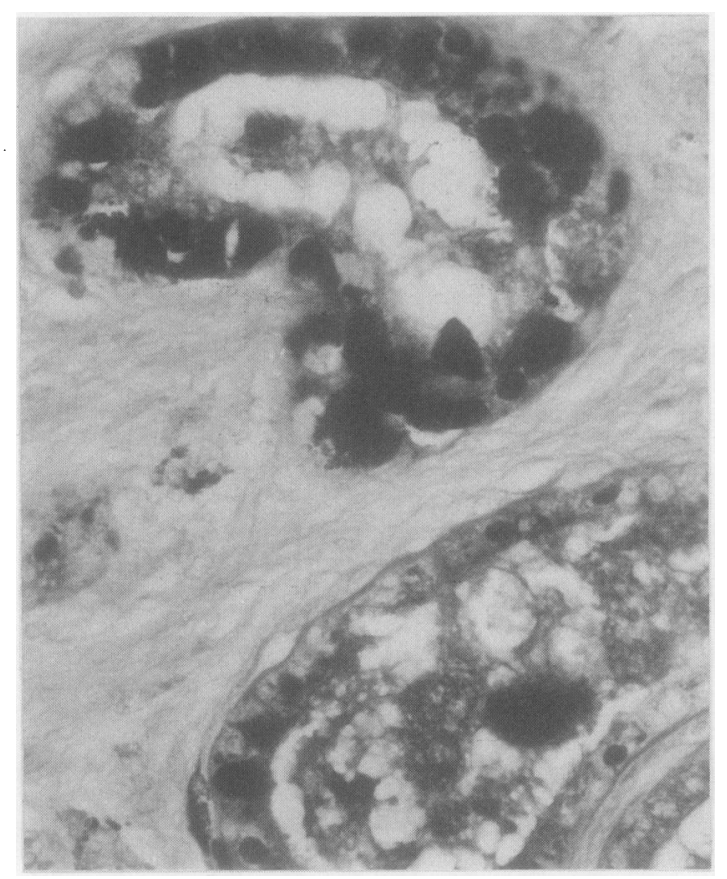

Fig 5 Ductules showing mucinous metaplasia of lining epithelium. (Alcian blue-periodic acid Schiff/diastase.)
Table 2 Clinical findings

\begin{tabular}{|c|c|c|c|c|}
\hline & & $\begin{array}{l}\text { With } \\
\text { vasitis }\end{array}$ & $\begin{array}{l}\text { Without } \\
\text { vasitis }\end{array}$ & p value \\
\hline $\begin{array}{l}\text { Age (years) } \\
\text { Mean (SD) }\end{array}$ & \multirow[t]{2}{*}{ Range } & $\begin{array}{l}32-45 \\
38 \cdot 4(3 \cdot 5)\end{array}$ & $\begin{array}{l}28-55 \\
38 \cdot 8(7 \cdot 3)\end{array}$ & $p=0.8$ \\
\hline $\begin{array}{l}\text { Interval between } \\
\text { vasectomy and }\end{array}$ & & & & \\
\hline reversal (years) & \multirow[t]{4}{*}{ Range } & $5-12$ & $0 \cdot 7-14$ & \\
\hline $\begin{array}{l}\text { Palpable lump } \\
\text { Sperm count }>2 \times 10^{6}\end{array}$ & & $\begin{array}{l}7 \cdot 9(2 \cdot 7) \\
12 / 17^{*}\end{array}$ & $\begin{array}{l}6 \cdot 9(4 \cdot 1) \\
6 / 18^{*}\end{array}$ & $\begin{array}{l}p=0.4 \\
p=0.03\end{array}$ \\
\hline or impregnation & & $6 / 17^{*}$ & $11 / 20^{*}$ & $p=0.52$ \\
\hline Ensuing pregnancies & & & 6 & $\mathrm{p}=0.38$ \\
\hline
\end{tabular}

*Denominator indicates number of patients examined.

reversal was also similar in the two groups: 7.9 (SD $2 \cdot 7$ ) and $6 \cdot 9$ (SD 4.1) respectively.

Twelve patients with vasitis nodosa and six without had palpable lumps at the vasectomy site. $\left(\chi^{2}=4 \cdot 9\right.$, $\mathrm{p}=0.03$ ) (table 2). In none of the patients were the lumps painful or tender to palpation.

After vasectomy reversal the patients were followed up for six to 15 months. During this time six of the patients without vasitis nodosa successfully impregnated their spouses as did three patients with vasitis nodosa $\left(\chi^{2}=0.76, p=0.38\right)$ (table 2$)$. Sperm counts between $2 \times 10^{6} / \mathrm{ml}$ and $69 \times 10^{6} / \mathrm{ml}$ were noted in three patients with vasitis and in five without. Persistent azoospermia or hypozoospermia $\left(<2 \times 10^{6}\right.$ spermatozoa $/ \mathrm{ml}$ ) was present in 11 patients with and in nine without vasitis nodosa.

\section{Discussion}

Present findings show that vasitis nodosa complicates about $50 \%$ of vasectomies, irrespective of the age of the patient or the interval between vasectomy and reversal. Associated histological abnormalities include sperm granulomas, mucinous metaplasia of the proliferating ductules, and hyperplasia of nerves in the perivasal tissues. The restoration of fertility after vasovasostomy does not seem to be affected by previous vasitis nodosa.

The prevalence of vasitis nodosa in the present study was slightly lower than the $66 \%$ reported by Taxy et al ${ }^{\beta}$ and Kiser et al. ${ }^{3}$ In both of these studies the interval between vasectomy and reversal ranged from one to 15 years. The incidence of vasitis nodosa does not seem to increase after the first few months following vasectomy, suggesting that vasitis develops, if at all, within this period. Civantos et al noted vasitis nodosa as early as one month after vasectomy. ${ }^{2}$

Although several mechanisms have been proposed ${ }^{1}$ to explain the pathogenesis of vasitis nodosa, it is generally believed that raised intravasal pressure, due to obstruction of the vas, causes disruption of the lining epithelium and extravasation of spermatozoa 
Vasitis nodosa and associated clinical findings

into the surrounding tissue. ${ }^{21}$ The spermatozoa elicit an intense inflammatory reaction which results in the formation of sperm granulomas. Ductules are thought to be formed by growth of epithelial cells from breaches in the mucosa of the vas into the inflamed tissue. Distension of ductules due to continued formation of spermatozoa probably causes the spermatocoeles. Chronic inflammation of the ductal epithelium may initiate the mucinous metaplasia that was observed in the present study. We encountered sperm granulomas only in association with vasitis nodosa, the prevalence being similar to that of previous studies. $^{812}$

The cause and clinical importance of the nerve hyperplasia and neuromas are unclear. Although the neuromas are probably traumatic in origin, their predominance in those patients who have had vasitis nodosa indicates that factors other than the surgery alone are likely to have a role. It is conceivable that the proliferating epithelium elaborates growth factors which induce hyperplasia of the perivasal nerves. Alternatively, the severe inflammation and the infiltration of nerves by proliferating ductules may exacerbate the surgical trauma and thereby promote the nerve hyperplasia and neuroma formation. Although pain and tenderness have been reported in association with vasitis nodosa,${ }^{13}$ none of the patients in this series presented with painful masses. The infiltration of nerves ${ }^{14-17}$ and blood vessels ${ }^{18}$ by ductules are features that may simulate metastatic adenocarcinoma of the prostate, which tends to spread along lymphatics in the adventitia of the vas. ${ }^{2}$ The typical ductal branching of vasitis nodosa and the presence of spermatozoa within the ducts and in the granulomas may help in distinguishing this process from carcinoma. ${ }^{3}$ Rarely, vasitis nodosa may be the site of arrest of malignant cells from a primary tumour in the ipsilateral testis. ${ }^{19}$

Silber found that the presence of sperm granulomas in the segment of vas excised during vasectomy reversal augured a favourable outcome. ${ }^{1220} \mathrm{He}$ suggested that the sperm granuloma acted as a "safety valve", relieving the high pressure in the testicular part of the vas, and thereby alleviating the effects of high intravasal pressure on the testis itself. We found no significant difference between the fertility of patients with, and those without, sperm granulomas in the excised segment of vas.

There were several patients in this study, who failed to impregnate their spouses, despite the recovery of sperm counts to normal or near normal levels. These results may reflect the relatively short period of follow up. Alternatively, the persistent infertility may be due to the development of antisperm antibodies, which can be detected in 50 to $70 \%$ of patients after vasectomy. ${ }^{521}$ This procedure is believed to disrupt the "blood-testis barrier" which normally shields the spermatozoa from the immune system..$^{22}$

We thank Dr R J Thompson for providing antibody to PGP 9.5.

\section{References}

1 Benjamin JA, Robertson TD, Cheetham JG. Vasitis nodosa: a new clinical entity simulating tuberculosis of the vas deferens. $J$ Urol 1943;49:575-82.

2 Civantos F, Lubin J, Rywlin AM. Vasitis nodosa. Archives of Pathology 1972;94:355-61.

3 Kiser GC. Fuchs EF, Kessler S. The significance of vasitis nodosa. J Urol 1986;136:42-4.

4 Graham JB, O'Connor VJ. Spermatic cord tumors: review of literature and a case of an unusual vas deferens tumor in an infertility problem. J Urol 1954;72:946-9.

5 Taxy JB. Vasitis nodosa. Arch Pathol Lab Med 1978;102:643-7.

6 Chapman ES, Heidger PM. Spermatic granuloma of vas deferens after vasectomy in rhesus monkeys and men. Urology 1979;13:629-39.

7 Philp T, Guillebaud J, Budd D. Late failure of vasectomy after two documented analyses showing azoospermic semen. $\mathrm{Br}$ Med J 1984;289:77-9.

8 Taxy JB, Marshall FF, Erlichman RJ. Vasectomy. Subclinical pathologic changes. Am J Surg Pathol 1981;5:767-72.

9 Rode J, Dhillon AP, Doran JF, Jackson P, Thompson RJ. PGP $9 \cdot 5$, a new marker for human neuroendocrine tumours. Histopathology 1985;9:147-58.

10 Levin HS. Testicular biopsy in the study of male infertility. Its current usefulness, histologic techniques, and prospects for the future. Hum Pathol 1979;10:569-84.

11 Olson AL. Vasitis nodosa. Am J Clin Pathol 1971;55:364-8.

12 Silber SJ. Microscopic vasectomy reversal. Fertil Steril 1977;28:1191-202.

13 Schmidt SS. Spermatic granuloma: an often painful lesion. Fertil Steril 1979;31:178-81.

14 Balogh $K$, Travis WD. The frequency of perineural ductules in vasitis nodosa. Am J Clin Pathol 1984;82:710-3.

15 Zimmerman KG, Johnson PC, Paplanus SH. Nerve invasion by benign proliferating ductules in vasitis nodosa. Cancer 983;51:2066-9.

16 Kovi J, Agbata A. Benign neural invasion in vasitis nodosa. JAMA 1974;228:1519

17 Goldman RL, Azzopardi JG. Benign neural invasion in vasitis nodosa. Histopathology 1982;6:309-15.

18 Balogh $\mathrm{K}$, Travis WD. Benign vascular invasion in vasitis nodosa. Am J Clin Pathol 1985;83:426-30.

19 Heaton JM, Maclennan KA. Vasitis nodosa-a site of arrest of malignant germ cells. Histopathology 1986;10:981-9.

20 Silber SJ. Sperm granuloma and reversibility of vasectomy. Lancet 1977;ii:588-9.

21 Samuel T, Rose NR. The lessons of vasectomy-a review. J Clin Lab Immunol 1980;3:77-83.

22 Anonymous. Safety of vasectomy [Editorial]. Lancet 1979;ii: 1057-8.

23 Lepow IH, Crozier R. Vasectomy: immunologic and pathophysiologic effects in animals and man. New York: Academic Press, 1979;581-95.

Requests for reprints to: Dr J Rode, Department of Histopathology, University College and Middlesex School of Medicine, Rockefeller Building, University Street, London WCIE 6JJ, England. 